\title{
(2) OPEN ACCESS \\ Novel case of a scleroderma-mimicking syndrome associated with gastrointestinal stromal tumour
}

\author{
Zaran Ahmad Butt, Wan Lin Ng, Kamal Osman, Donough Howard
}

Department of Rheumatology, Beaumont Hospital, Dublin, Leinster, Ireland

\section{Correspondence to} Dr Zaran Ahmad Butt; svcsm4butt.zaran@gmail.com

Accepted 22 February 2021

Check for updates

(c) BMJ Publishing Group Limited 2021. Re-use permitted under CC BY-NC. No commercial re-use. See rights and permissions. Published by BMJ.

To cite: Butt ZA, Ng WL, Osman $\mathrm{K}$, et al. BMJ Case Rep 2021;14:e240211. doi:10.1136/bcr-2020240211

\section{SUMMARY}

We report a case of a 54-year-old man who developed an atypical systemic syndrome involving Raynaud's phenomenon, pulmonary fibrosis and skin thickening. These features were initially suggestive of newly diagnosed scleroderma. However, he displayed atypical clinical features of same, antinuclear antibody was negative and symptoms were refractory to various immunosuppressive therapies. CT imaging revealed a gastric mass, which later proved to be a gastrointestinal stromal tumour (GIST). Resection of the GIST leads to minimal symptomatic improvement. Surveillance imaging 1 year later revealed metastatic deposits. He was subsequently initiated on imatinib therapy, which led to a rapid improvement in fibrotic changes within weeks. While there have been previous descriptions of paraneoplastic fibrotic disorders, this is the first description of a scleroderma mimic in the setting of a GIST. It highlights an important potential overlap in the pathogenesis of these disease processes and the potential efficacy of tyrosine kinase inhibitors for scleroderma-like fibrotic disorders.

\section{BACKGROUND}

Although rare overall, gastrointestinal stromal tumour (GIST) is the most common mesenchymal tumour of the gastrointestinal (GI) tract. ${ }^{1}$ They originate from interstitial cells of Cajal. Most are discovered incidentally on CT imaging performed for other reasons. A majority of GIST demonstrates activating mutations of receptor tyrosine kinases, including c-Kit (CD117) and plateletderived growth factor receptor alpha (PDGFRA). ${ }^{1}$ These serve as important therapeutic targets, with imatinib approved for the management of unresectable or advanced GIST. ${ }^{2}$

Systemic sclerosis (scleroderma) is an idiopathic fibrotic disorder characterised by excess collagen deposition in various tissues, including the skin, lungs, kidneys and GI tract. There is emerging evidence highlighting dysfunctional fibroblasts being fundamental to this disease process, and an increasing awareness of the complex interplay of these fibroblasts with other cells and inflammatory mediators is being recognised. ${ }^{3}$ This unique case serves to further develop this awareness and to highlight a potential role for imatinib in disrupting these pathological interactions.

\section{CASE PRESENTATION}

A 54-year-old previously healthy Caucasian man was referred to our rheumatology clinic with a 3-month history of Raynaud's phenomenon affecting the hands and feet. He also described arthralgia affecting the small joints of the hands, as well as a dry cough and fatigue. System review was notable for an influenza-like illness prior to the onset of his symptoms. He also had a long-standing facial rash, which he reported was intermittently present and responded to topical steroids.

He had no significant medical history or surgical history, and he took no regular or over-the-counter medications. His mother had asthma and hypothyroidism. His sister also had hypothyroidism, while his brother was diagnosed with thyroid cancer at the age of 45 . He was an ex-smoker with a 20-pack-year history, and he drank 14 units of alcohol per week. He denied any intravenous drug use.

On physical examination, his vital signs were within normal limits. Triphasic colour change of Raynaud's was noted in the hands. There was also 'puffiness' of the fingers and dorsum of the hand but no clear sclerodactyly. There was no focal tenderness, digital ulcers or synovitis. There was no focal weakness apart from decreased grip strength. Cardiorespiratory, abdominal, neurological and thyroid exam were unremarkable.

\section{INVESTIGATIONS}

His bloods were significant for a raised creatine kinase (429U/L; reference range: 39-308 U/L) and an IgA paraprotein band. Urine was negative for Bence-Jones proteins, and no lytic lesions were identified on skeletal survey. Bone marrow trephine biopsy was also unremarkable, demonstrating 5\% plasma cells. Electromyelogram of the upper and lower limbs revealed no evidence of myopathic changes or denervation.

Full blood count, renal and liver profile, $\mathrm{C}$ reactive protein $(3.8 \mathrm{mg} / \mathrm{L}$; reference range: $0-5 \mathrm{mg} / \mathrm{L})$, erythrocyte sedimentation rate $(5 \mathrm{~mm} /$ hour; reference range: $1-12 \mathrm{~mm} /$ hour), C3/C4 level, cryoglobulins, Anti-Neutrophil Cytoplasmic Antibodies (ANCA), rheumatoid factor, anti-CCP, anti-tissue transglutaminase antibody, extended myositis panel and connective tissue screen (antinuclear antibody (ANA), anti-Scl-70, anticentromere, anti-DsDNA, anti-RNP, anti-SM, anti-RO and anti-La) were all within normal limits. Diagnostic nailfold capillaroscopy showed no evidence of tortuosity, capillary dropout or evidence of neoangiogenesis.

His chronic cough prompted pulmonary function testing (PFT), which was consistent with a restrictive pattern (forced vital capacity (FVC) 122\% predicted, forced expiratory volume in $1 \mathrm{~s}\left(\mathrm{FEV}_{1}\right) /$ FVC 77\% predicted and Diffusing capacity of Lung for Carbon Monoxide (DLCO) 68\% predicted). CT thorax showed multiple mildly enlarged mediastinal 


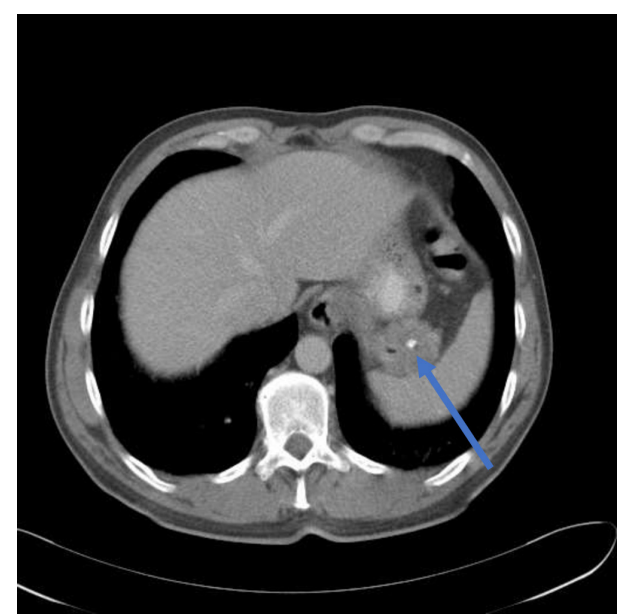

Figure $1 \mathrm{CT}$ abdomen demonstrating a mass-like thickening in the region of the gastric fundus with a focus of calcification (arrow).

and axillary nodes, which were felt to be likely reactive in nature. There was also very soft airspace disease at both lung bases and early bilateral lower-lobe bronchiolar dilatation.

\section{DIFFERENTIAL DIAGNOSIS}

His initial diagnosis was unclear but was most consistent with an undifferentiated connective tissue disorder associated with myositis, Raynaud's syndrome and mild interstitial lung disease (ILD). This clinical picture suggested possible ANA-negative systemic sclerosis or a mimic of same. Over the next 3 months, he had increasingly frequent Raynaud's episodes, which were refractory to nifedipine. He also reported worsening cough, new pyrosis, and an unintentional weight loss of $23 \mathrm{lbs}$ in 6 months. The skin on his hands also became significantly thickened. It was clinically consistent with a modified Rodnan Skin Score (mRSS) of 3 (severe thickness). This is a standardised outcome measure for severity of skin disease in scleroderma. ${ }^{4}$ Interestingly, this thickening affected the dorsum of the hands and fingers but spared the skin distal to the proximal interphalangeal joints, unlike in true sclerodactyly. Trials of repeated iloprost infusions, azathioprine, mycophenolic acid, prednisolone and sildenafil all led to minimal sustained improvement in symptoms.

CT thorax, abdomen and pelvis (TAP) revealed thickening of the gastric fundus with associated calcification (figure 1). There was also interval increase in the size of his mediastinal and axillary nodes and evidence of worsening ILD (figure 2). Excisional biopsy of a right axillary node showed reactive features with no atypical lymphoid cells seen. Bronchoalveolar lavage was unremarkable. Gastroscopic biopsy of the fundal mass revealed morphology and immunohistochemistry, which was consistent with a GIST, suggesting that his atypical inflammatory disorder may be a paraneoplastic phenomenon.

\section{TREATMENT}

He subsequently underwent laparoscopic partial gastrectomy. Histopathological findings were consistent with a grade 1 GIST at stage pT2 (figure 3). The mass was breaching the serosal surface but was well circumscribed with clear surgical margins.

Four weeks later, his weight stabilised; however, he reported more frequent Raynaud's flares despite continuing mycophenolic acid and prednisolone postsurgery. His hands also remained swollen and thickened, but no digital ulcerations were noted. He had ongoing myopathy and dry cough and worsening

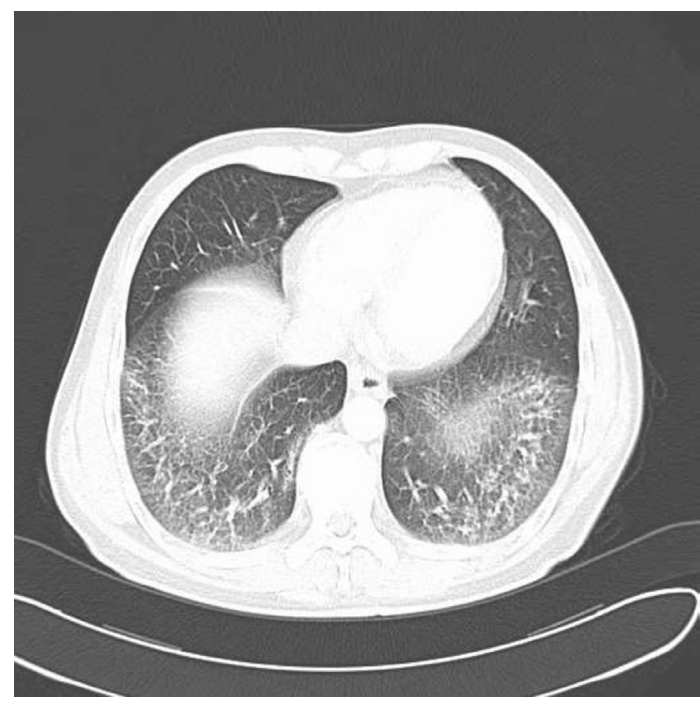

Figure 2 CT thorax demonstrating increased ground-glass density change within the bilateral lower lobes with some interstitial thickening, suggestive of worsening interstitial lung disease.

dyspnoea on exertion. He also had an acute episode of microscopically confirmed pseudogout affecting the right knee. Radiographic imaging of the knee was consistent, showing evidence of chondrocalcinosis. Repeat CT TAP 10 months postgastrectomy showed no GIST recurrence but persistent ground-glass opacification of the lung bases. Repeat PFT showed worsening interstitial disease (DLCO 50\% predicted and normal $\mathrm{FEV}_{1} / \mathrm{FVC}$ ). Right heart catheterisation showed no evidence of pulmonary hypertension.

One year later, surveillance CT TAP was highly concerning for GIST recurrence in the form of diffuse peritoneal disease (figure 4). Diagnostic laparoscopy with biopsy confirmed metastatic GIST recurrence. No mitoses were seen histologically, suggesting low risk of further metastatic spread. The patient was medically treated with imatinib $100 \mathrm{mg}$ once daily in combination with prednisolone $10 \mathrm{mg}$ once daily. He reported a

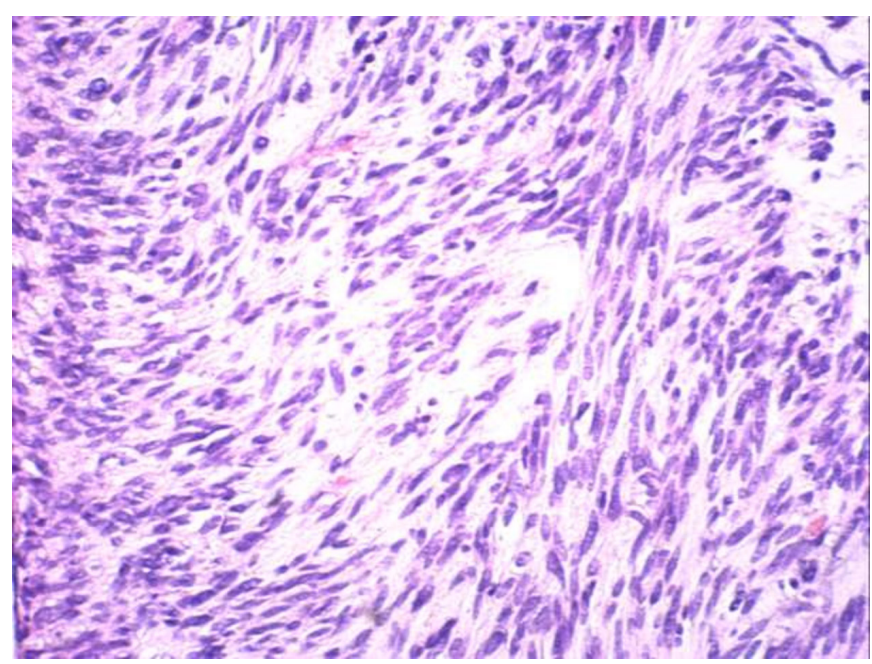

Figure 3 Histopathological specimen of the gastric mass removed during laparoscopic partial gastrectomy. Bland spindle cell population arranged in fascicles is seen. Mitoses are not prominent. Immunohistochemistry showed strong diffuse staining for CD117 and D0G1, while SMA and S100 were negative. These features are consistent with a low-grade gastrointestinal stromal tumour. 


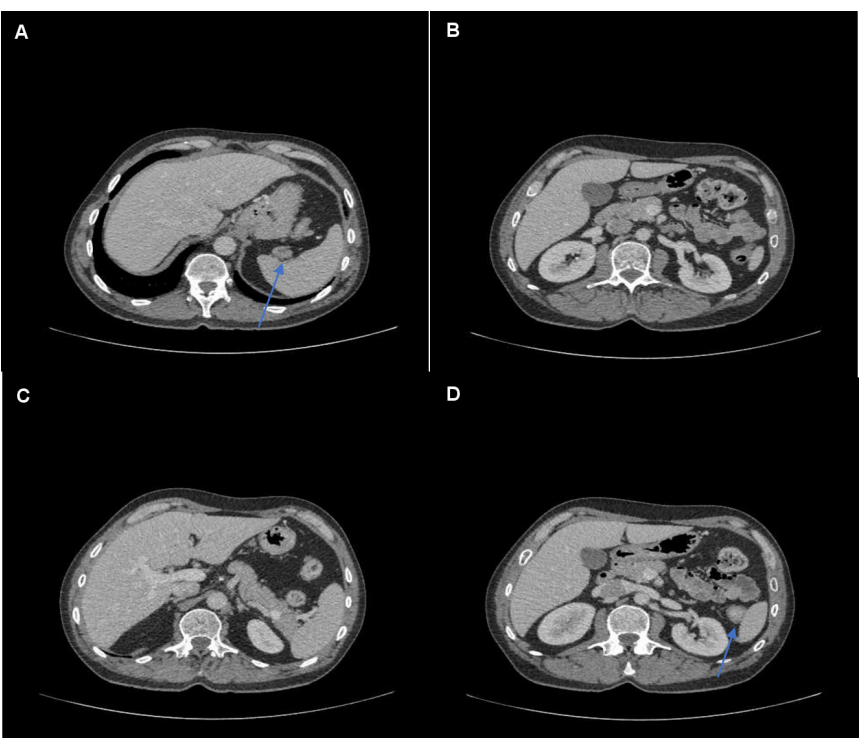

Figure $4 \mathrm{CT}$ abdomen and pelvis demonstrating a new soft tissue nodule in the left upper quadrant $(A)$ and multiple tiny scattered deposits on the surface of the liver $(B, C)$ and spleen (D).

significant improvement in his Raynaud's episodes and dyspnoea with this regime within 1 month. Hand examination revealed an improvement in mRSS from grade 3 to grade 1 skin thickening (figure 5).

\section{OUTCOME AND FOLLOW-UP}

Repeat CT TAP 3 months later was reassuring (figure 6). Despite this positive response to imatinib, he had significant tolerability issues. He reported recurrent episodes of high fevers, nausea and malaise. These persisted when imatinib was substituted with sunitinib. His fibrotic symptoms recurred when therapy was held; hence, a lower dose of imatinib (100 mg once daily on a week-on/week-off basis) with prednisolone $50 \mathrm{mg}$ once daily was trialled. When accompanied by high-dose steroids, he once again had clinical improvement while taking imatinib, and side effects were manageable. He is frequently followed up by our

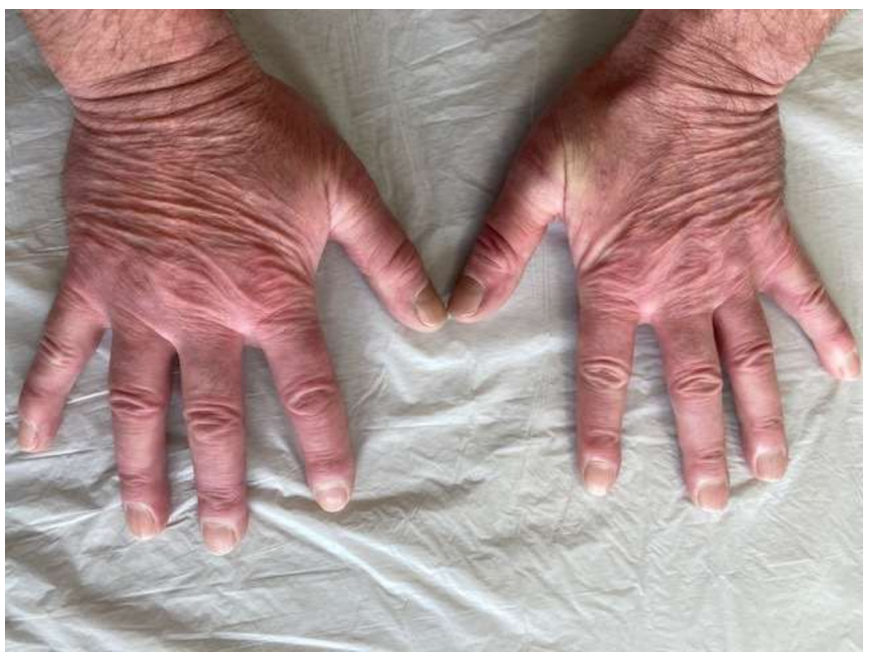

Figure 5 Image showing the patient's hands 1 month after starting imatinib therapy. Mild skin thickness (grade 1 modified Rodnan Skin Score (mRSS)) is demonstrated, compared previously when the skin could not be pinched into a fold (grade 3 mRSS).

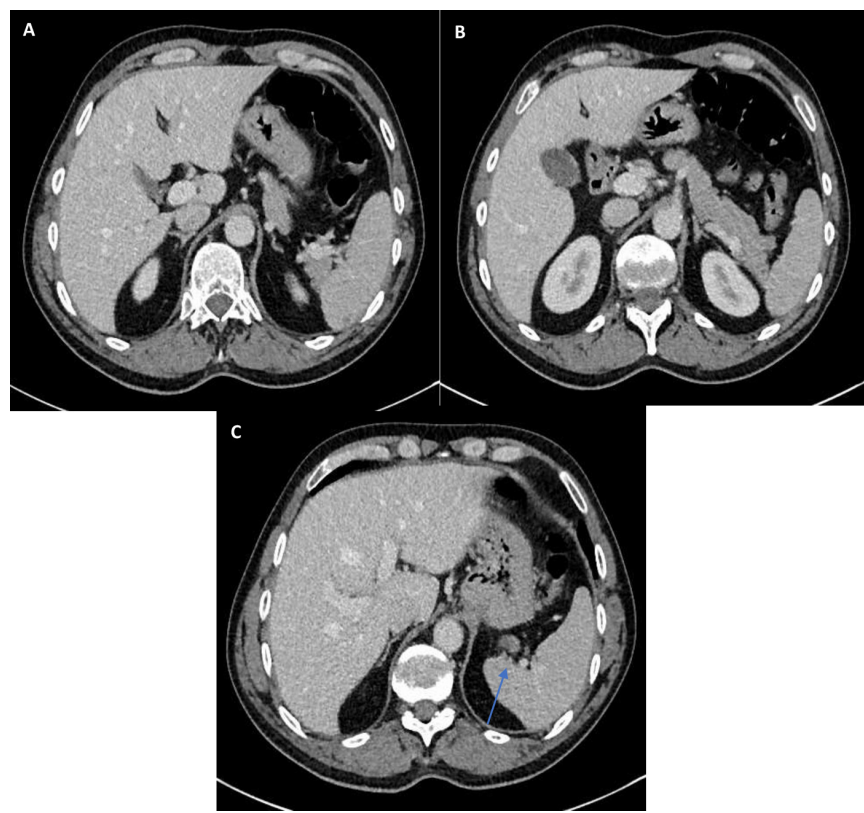

Figure $6 \mathrm{CT}$ images demonstrating an interval reduction in the size of hepatic deposits (A, B). There is also no evidence of new or enlarging peritoneal disease and an unchanged splenic deposit (C).

rheumatology service with the aim of tapering his daily dose of prednisolone as tolerated.

\section{DISCUSSION}

We present an interesting case of a scleroderma-mimicking syndrome, which appears to be a paraneoplastic phenomenon associated with GIST. While fibrotic skin changes were present, these fell short of a definitive diagnosis of scleroderma according to the 2013 American College of Rheumatology/European League Against Rheumatism (ACR/EULAR) criteria for the classification of systemic sclerosis, ${ }^{5}$ as the fibrotic skin changes did not extend to the distal finger and ANA was negative.

The patient had a significant clinical response only to imatinib therapy, with minimal response to vasodilator or immunosuppressive therapies. Tyrosine kinase inhibitors are the standard treatment for metastatic or unresectable GIST according to the most recent European Society for Medical Oncology guidelines for the management of GIST. ${ }^{2}$ The recommended dose is $400 \mathrm{mg}$ daily or $800 \mathrm{mg}$ daily depending on the underlying mutation. Our patient was treated with low-dose imatinib (100 mg by mouth once daily on a week-on/week-off basis) in combination with $50 \mathrm{mg}$ prednisolone once daily due to tolerability issues. These guidelines also recommend complete surgical resection of localised resectable GIST. Adjuvant therapy with imatinib is recommended for 3 years for high-risk patients. Our patient had a low-risk tumour resected initially ( $<2 \%$ recurrence risk) and therefore received no adjuvant therapy.

To our knowledge, this is the first reported case of GISTrelated scleroderma-like syndrome in the literature, making this a unique and valuable case. Rare cases of paraneoplastic syndromes associated with GIST have been reported: hypoglycaemia, ${ }^{6-10}$ alopecia areata ${ }^{11}$ and hypercalcaemia. ${ }^{12}$ Samimi et $a l^{13}$ described a case of GIST-related dermatomyositis. Similar to our case, their patient had biopsy-proven GIST, which was c-Kit-positive. Interestingly, their patient had minimal response to imatinib, highlighting the heterogeneity of GIST. ${ }^{14}$ 
An interesting hypothesis to explain the observed temporal clustering of GIST and the fibrotic disorder seen in this case is the probable commonality of cytokines driving these two processes. Platelet-derived growth factor (PDGF) is a well-studied cytokine with important roles in various systems and cellular processes. ${ }^{15}$ This includes prominent roles in early development, angiogenesis and haematopoiesis. Aberrant PDGF signalling however is implicated in disease processes such cancers, fibrotic disorders and vascular disease. This is thought to be due to the critical role of PDGF in autocrine/paracrine signalling among fibroblasts, vascular smooth muscle cells and endothelial cells. The majority $(95 \%)$ of GIST displays activating mutations in tyrosine kinases such as c-Kit or PDGFRA. ${ }^{16}$ PDGFRA mutations are particularly common in gastric GIST and thought to be central in promoting neoplastic cell proliferation and resistance to apoptosis.

While the precise pathogenesis of scleroderma remains poorly understood, increasing evidence hints at a population of activated fibroblasts being central to the fibrotic changes seen in the disease. These fibroblasts are thought to communicate with smooth muscle, endothelial and immune cells through a broad variety of mediators, including interleukin (IL)-4, IL-6, transforming growth factor- $\beta$ and PDGF. ${ }^{17-20}$ The factors precipitating this complex interaction and the relative importance of these mediators remain unclear. Interestingly, cultured scleroderma fibroblasts have been shown in vivo to display upregulated PDGF signalling, with inhibition of this signalling leading to restoration of a normal fibroblast phenotype. ${ }^{21}$ This suggests

\section{Patient's perspective}

On Christmas Eve, I was in my mother's house with the rest of my family when someone asked me what was going on with my hands. When I looked at them, they were huge. That was the start. Over the next few days, they got worse. My general practitioner referred me to a rheumatologist. He did all the required blood work but got no answers. I was getting worse by the day, to the point where I could not open a carton of milk or do any nimble tasks, like pick up a coin. This went on for a while as the bloods were not telling us anything. Eventually, I went on a high dose of steroids and got great relief. As time went on, my feet and my breathing were affected also. I also developed rashes, mainly on my face but also on my body. We tried a couple of different medications to no avail. In 2017, we found a gastrointestinal stromal tumour (GIST). This was removed, but unfortunately, the GIST later came back. Imatinib was recommended for me. I am still currently on this after initial problems, having high-temperature spikes. The skin on my hands has loosened, which has allowed me to do things like use a paint brush. I am hopeful things will continue to improve.

Learning points

- Gastrointestinal stromal tumour (GIST) is a heterogenous tumour that can be associated with scleroderma-like fibrotic disorders.

- Platelet-derived growth factor plays an important role in the pathogenesis of both GIST and scleroderma.

- Imatinib has the potential to be a therapeutic option in patients with scleroderma and scleroderma-mimicking syndromes. a crucial role for PDGF in promoting and sustaining the scleroderma fibroblast.

Imatinib is a tyrosine kinase inhibitor, which acts to antagonise tyrosine kinases such as c-Kit, PDGFRA, Bcr-Abl and c-Abl. ${ }^{22}$ This action explains its efficacy in treating metastatic GIST. There is much excitement about the potential efficacy of imatinib in scleroderma due to greater awareness of the important role of PDGF signalling in its pathogenesis. This is demonstrated by the effectiveness of imatinib in treating our patient's systemic syndrome. Early in vivo studies have been promising ${ }^{23}$; however, the few clinical trials that have been done to date have produced mixed results, with one trial terminating prematurely due to safety concerns. ${ }^{25}$ This highlights the need for further empirical work to classify markers, which identify the patients who may benefit most from imatinib therapy while minimising the side effects.

Contributors ZAB: Conceptualised and designed the work, collected and analysed relevant clinical and radiological data and chief author of the final manuscript. WLN: Made significant contributions to editing of manuscript drafts. DH: Chief supervisor. DH has considerable expertise in the areas of rheumatology and connective tissue disease and contributed to work design and final approval of the version published. KO: Contributed to collection and interpretation of histopathological data.

Funding The authors have not declared a specific grant for this research from any funding agency in the public, commercial or not-for-profit sectors.

Competing interests None declared.

Patient consent for publication Obtained.

Provenance and peer review Not commissioned; externally peer-reviewed.

Open access This is an open access article distributed in accordance with the Creative Commons Attribution Non Commercial (CC BY-NC 4.0) license, which permits others to distribute, remix, adapt, build upon this work non-commercially, and license their derivative works on different terms, provided the original work is properly cited and the use is non-commercial. See: http://creativecommons.org/ licenses/by-nc/4.0/.

\section{REFERENCES}

1 Parab TM, DeRogatis MJ, Boaz AM, et al. Gastrointestinal stromal tumors: a comprehensive review. J Gastrointest Oncol 2018;10:144-54.

2 Casali PG, Abecassis N, Aro HT, Bauer S, et al. Gastrointestinal stromal tumours: ESMO-EURACAN clinical practice guidelines for diagnosis, treatment and follow-up. Ann Oncol 2018;29:iv68-78.

3 Pattanaik D, Brown M, Postlethwaite BC, et al. Pathogenesis of systemic sclerosis. Front Immunol 2015;6:272.

4 Khanna D, Furst DE, Clements PJ, et al. Standardization of the modified Rodnan skin score for use in clinical trials of systemic sclerosis. J Scleroderma Relat Disord 2017:2:11-18

5 van den Hoogen F, Khanna D, Fransen J, et al. 2013 classification criteria for systemic sclerosis: an American College of Rheumatology/European League against rheumatism collaborative initiative. Arthritis Rheum 2013;65:2737-47.

6 Singhal A, Hadi R, Mehrotra K, et al. Paraneoplastic hypoglycaemia: a rare manifestation of pelvic gastrointestinal stromal tumour. J Clin Diagn Res 2017; 11:XD01-XD02.

7 Dimitriadis GK, Gopalakrishnan K, Rao R, et al. Severe paraneoplastic hypoglycemia secondary to a gastrointestinal stromal tumour masquerading as a stroke. Endocrinol Diabetes Metab Case Rep 2015;2015:150062.

8 Escobar GA, Robinson WA, Nydam TL, et al. Severe paraneoplastic hypoglycemia in a patient with a gastrointestinal stromal tumor with an exon 9 mutation: a case report. BMC Cancer 2007;7:13

9 Wilson JM, Ginsberg J, Cutts K, et al. A case of non-islet cell tumor hypoglycemia (NICTH) associated with gastrointestinal stromal tumor (GIST). Am J Case Rep 2017; 18:984-8.

10 Yamasaki $\mathrm{H}$, Itawaki A, Morita $\mathrm{M}$, et al. A case of insulin-like growth factor 2-producing gastrointestinal stromal tumor with severe hypoglycemia. BMC Endocr Disord 2020;20:60

11 Axel J, Weickert U, Dancygier H. Trommelschlegelfinger und alopecia areata ALS paraneoplastisches Früh-Phänomen bei Weichteiltumor (GIST) des Ösophagus. Dtsch med Wochenschr 2005;130:2380-3.

12 Jasti P, Lakhani VT, Woodworth A, et al. Hypercalcemia secondary to gastrointestinal stromal tumors: parathyroid hormone-related protein independent mechanism? Endocr Pract 2013;19:e158-62. 
13 Samimi M, Nseir A, Kerdraon $R$, et al. Tumeur stromale duodénale révélée PAR une dermatomyosite paranéoplasique. Gastroentérologie Clinique et Biologique 2008;32:1018-20.

14 Heinrich MC, Corless CL, Demetri GD, et al. Kinase mutations and imatinib response in patients with metastatic gastrointestinal stromal tumor. J Clin Oncol 2003;21:4342-9.

15 Andrae J, Gallini R, Betsholtz C. Role of platelet-derived growth factors in physiology and medicine. Genes Dev 2008;22:1276-312.

16 Miettinen M, Lasota J. Gastrointestinal stromal tumors: review on morphology, molecular pathology, prognosis, and differential diagnosis. Arch Pathol Lab Med 2006;130:1466-78.

17 Feghali CA, Bost KL, Boulware DW, et al. Mechanisms of pathogenesis in scleroderma. I. overproduction of interleukin 6 by fibroblasts cultured from affected skin sites of patients with scleroderma. J Rheumatol 1992;19:1207-11.

18 Needleman BW, Wigley FM, Stair RW. Interleukin-1, interleukin-2, interleukin-4, interleukin-6, tumor necrosis factor alpha, and interferon-gamma levels in sera from patients with scleroderma. Arthritis Rheum 1992;35:67-72.

19 Brown M, O'Reilly S. The immunopathogenesis of fibrosis in systemic sclerosis. Clin Exp Immunol 2019;195:310-21.
20 Liakouli V, Cipriani P, Marrelli A, et al. Angiogenic cytokines and growth factors in systemic sclerosis. Autoimmun Rev 2011;10:590-4.

21 Svegliati S, Cancello R, Sambo P, et al. Platelet-derived growth factor and reactive oxygen species (ROS) regulate Ras protein levels in primary human fibroblasts via ERK1/2.J Biol Chem 2005:280:36474-82.

22 Kameda H, Suzuki M, Takeuchi T. Platelet-derived growth factor as a therapeutic target for systemic autoimmune diseases. Drug Target Insights 2007;2:117739280700200-47.

23 Soria A, Cario-André M, Lepreux S, et al. The effect of imatinib (Glivec) on scleroderma and normal dermal fibroblasts: a preclinical study. Dermatology 2008:216:109-17.

24 Hinchcliff M, Huang C-C, Ishida W, et al. Imatinib mesylate causes genome-wide transcriptional changes in systemic sclerosis fibroblasts in vitro. Clin Exp Rheumatol 2012;30:S86-96.

25 Bournia V-K, Evangelou K, Sfikakis PP. Therapeutic inhibition of tyrosine kinases in systemic sclerosis: a review of published experience on the first 108 patients treated with imatinib. Semin Arthritis Rheum 2013;42:377-90.

Copyright 2021 BMJ Publishing Group. All rights reserved. For permission to reuse any of this content visit https://www.bmj.com/company/products-services/rights-and-licensing/permissions/

BMJ Case Report Fellows may re-use this article for personal use and teaching without any further permission.

Become a Fellow of BMJ Case Reports today and you can:

- Submit as many cases as you like

- Enjoy fast sympathetic peer review and rapid publication of accepted articles

- Access all the published articles

- Re-use any of the published material for personal use and teaching without further permission

\section{Customer Service}

If you have any further queries about your subscription, please contact our customer services team on +44 (0) 2071111105 or via email at support@bmj.com.

Visit casereports.bmj.com for more articles like this and to become a Fellow 